\title{
La novel la històrica en les lletres valencianes: usos del passat en la construcció cultural contemporània
}

\section{The historical novel in the Valencian letters: uses of the past in contemporary cultural construction}

\author{
M. Àngels FrancÉs DíEZ \\ angels.frances@gcloud.ua.es
}

Universitat d'Alacant

Institut Interuniversitari de Filologia Valenciana

En el llibre Funcions del passat en la literatura catalana contemporània. Institucionalitzacions, representacions $i$ identitat (2015), els editors Josep-Anton Fernàndez i Jaume Subirana descriuen tres eixos d'interés pels temps pretèrits que determinen importants aportacions a la cultura occidental contemporània: en primer lloc, la dels Estudis Culturals britànics; en segon lloc, la del debat entorn de l'Holocaust i els conceptes d'oblit i trauma; en tercer lloc, l'ampliació francesa del camp de la història fins als denominats usos socials del passat i l'emergència paral lela de la sociologia de la cultura de Pierre Bourdieu. Així mateix, citen diversos autors que investiguen les relacions entre passat i construcció identitària, com ara Gellner, Anderson, Hobsbawm i Ranger o Smith, gràcies als quals «els estudis sobre les nacions han donat un gir decisiu, i s'ha imposat la perspectiva de les cultures nacionals com a construccions històriques» (Fernández \& Subirana 2015: 7).

En efecte, segons exposa Benedict Anderson, la nació «és imaginada perquè ni els membres de la nació més petita mai no arribaran a conéixer la major part de la resta dels seus compatriotes, ni els seran presentats, ni tan sols sentiran parlar-ne mai i, tanmateix, en la ment de cada un viu la imatge de la seua comunió» (Balaguer 2007: 13). Les bases de creació de les nacions són, generalment, una llengua, un passat històric, un territori i una literatura. De les passes d'aquest procés, segons les enumera Balaguer (2007: 19-20), ens interessa especialment la que se centra en l'estudi de la història (investigació del passat incidint en els aspectes particulars i diferencials de la identitat de la nació) i el de la publicació de llegendes, mites i tota mena de literatura popular de la col lectivitat en qüestió. Aquest és el material primari amb el qual es bastirà l’imaginari nacional, i la novel la històrica conjumina justament tots dos aspectes, fent ús del passat com a marc i actant en el procés de creació literària i de construcció de referents col lectius. 
El monogràfic que segueix és una mostra d'aquesta operació creativa des de l'òptica valenciana. En són objecte d'estudi novel les que, situades majoritàriament en l'espai de les comarques centrals, revisen moments clau del nostre passat i amb una càrrega identitària important, com ara la revolta de les Germanies (segle XVI), el convuls segle XVII (amb una profunda interrogació sobre les nocions de pecat i culpa i la impossible lluita entre carn i esperit, sota l'atenta mirada dels representants eclesiàstics), el segle XVIII o de les llums (on l'ambició científica conduirà tenebrosos personatges a temptar els límits de la raó i l'ètica), el segle XIX (fins on arriben llargues nissagues que es remunten als inicis de l'edat Moderna i on els esdeveniments històrics conviuen amb el realisme màgic) i, també, el segle XX, que ja fa un temps que és matèria històrica de primer ordre per explicar-nos el present (sobretot, en relació amb la guerra civil, la postguerra i la Transició).

La majoria d'aquestes novel les contenen una càrrega important de creació identitària que, segons Palau (2006: 125), "és una manera d’interpretació del món per modificar-lo, perquè la nació no expressa la seva cultura, sinó que és la cultura la que produeix la nació.” Perquè la bona literatura que aquestes obres representen "canalitza emocions, transforma la percepció del passat i del present, canvia i reorganitza grups o en crea de nous, altera cultures emfasitzant uns aspectes o fent-ne d'altres comprensibles i lògics" (Palau 2006: 125). Els autors analitzats en els articles del monogràfic (Josep Lozano, Vicent Josep Escartí, Anna Moner, Víctor Labrado, Joan Oleza, Josep Bertomeu, Josep Franco, Francesc Bayarri, Francesc Bodí i Joanjo Garcia) trien per a nosaltres, doncs, espais i moments històrics que transformen la nostra percepció del passat i ens expliquen, en certa manera, el present que vivim. Algunes de les obres analitzades s'insereixen de manera prototípica en la categoria de novel la històrica (és el cas, per exemple, de les propostes de Lozano i Escartí, ambdós amb ingredients de realisme màgic); d'altres, són permeables a altres perspectives (com el gènere gòtic que impregna Les mans de la deixebla, de Moner, que més que representar esdeveniments històrics concrets prefereix reflexionar sobre la filosofia i la cultura de l'època), i d'altres se situen en les fronteres del model, bé per la proximitat del passat que representen (com ara les novel les ambientades en la Transició) o per l'alta dosi de material documental que les aproxima a la no ficció (en el cas d'algunes obres de Víctor Labrado). No obstant això, el que totes comparteixen és l'ús del passat com a marc d'inspiració per a reflexionar sobre la societat valenciana, per a interrogar-se sobre construccions identitàries i, sovint, sobre la part més fosca de l'ésser humà, condicionada per un context lluny del present però on aquest s'emmiralla d'alguna manera. Són textos que "posen en circulació relats compartits, formes i expressions conegudes, arquetipus humans, tòpics... [i, per tant,] contribueixen a crear i enfortir una comunitat» (Balaguer 2007: 12). I, juntament amb la producció d'altres autors valencians que també s'aproximen a la història com a marc de reconstrucció del nostre passat compartit (Ferran Garcia-Oliver, Joan Olivares, Eduard Mira, Martí Domínguez o Silvestre Vilaplana, per esmentar-ne només alguns), denoten l'interés actual per re/escriure'l i usar l'artifici del llenguatge (que té aroma d'oralitat antiga i ingredients d'acció i aventura) per parlar-nos sobre què vàrem ser i preguntar-nos què som ara, i així col laborar en la construcció de la nostra percepció cultural col lectiva. 
M. Àngels Francés Díez. La novel la històrica en les lletres valencianes: usos del passat en la construcció cultural contemporània

\section{Bibliografia}

Balaguer, E. (2007) «Literatura i imaginari nacional», Premi Joan Santamaria 2007. Assaig breu, Barcelona, La Busca edicions, p. 7-63.

Fernàndez, J.-A. \& Subirana, J. (2015) «Presentació», dins Fernàndez, J.-A. / Subirana, J. (eds.) Funcions del passat en la cultura catalana contemporània, Lleida, Punctum, p. 7-18.

SCRIPTA, Revista internacional de literatura i cultura medieval i moderna, núm. 14/ desembre 2019 /pp. $289-291$ ISSN: 2340-4841 · doi:10.7203/SCRIPTA.14.16371 